\title{
Book Review. Development and Connection in the Time of COVID-19 Walther, C. C. (2021). Development and Connection in the Time of COVID-19: Corona's Call for Conscious Choices. Springer Nature. ISBN: 978-3-030-53,640-4 Pages: XXV, 177
}

\section{Deniza Alieva ${ }^{1}$}

Published online: 10 May 2021

(C) The International Society for Quality-of-Life Studies (ISQOLS) and Springer Nature B.V. 2021

In 2020, the world community was faced with a global problem - a pandemic. This significantly influenced all vital aspects of the life of the planet's population, changing the quality of life and increasing the gaps between countries, social groups and even individuals. We can expect that the pandemic will have a positive impact on such a component of the quality of life as the state of the natural environment. This was facilitated, in particular, by a decrease in the rate of industrial production, a decrease in the volume of emissions and discharges of pollutants into the atmosphere, water, and soil. However, the pandemic had a negative impact on other components of the quality of life of the population.

The book Development and Connection in the Time of COVID-19 by Cornelia C. Walther analyzes the current situation in the world from different perspectives. The idea that everything and everybody in the world are interconnected runs through the whole book as a red line. Indeed, as the reader delves into the book, one sees and understands the nature of these connections more clearly and starts agreeing with the opinion of the author.

The book is divided in four chapters, each of those is dedicated to one of the elements of the puzzle or to interaction between them. The first chapter discusses the previous experience the humanity had with infectious diseases and the importance of extracting lessons from it. Financial health and financial well-being are considered in the context of their impact on public health. The author clearly demonstrates how the difference between the incomes of the population in different countries can exacerbate the consequences of a pandemic. In particular, limited access to medicine, poor

Deniza Alieva

deniza.alieva@gmail.com

1 Management Development Institute of Singapore in Tashkent, 28, Bunyodkor Ave., Chilanzar district, Tashkent, Uzbekistan 100185 
nutrition, lack of a developed health system and food problems are noted. The role of supranational institutions in current crisis is also discussed.

The second chapter focuses on the four principles that make the world order work: connection, change, continuum, and complementarity. They set the stage for subsequent discussions in the book and provide a lens through which the phenomenon of the pandemic is studied. On the other hand, four dimensions are presented that affect human being and, as a result, our perception and actions during the pandemic. It also discusses the changes in the perception of oneself and others that occurred in that period, and assesses the importance of the components of the institutional P-Puzzle: Priorities, People, Positions and Programs followed by the Power.

The third chapter evaluates the impact of the pandemic on the aforementioned dimensions, both from the perspective of individuals and across society. Cornelia C. Walther describes how people reacted to news about a pandemic by strengthening some features and weakening others, and also assesses the importance of such concepts as trust, cooperation or the common good. The influence of beliefs on the perception of reality and on human behavior is discussed, and the importance of digitalization and the Internet during a pandemic is evaluated. The Internet became a window to the world for those who were locked in quarantined homes, allowed them to communicate with loved ones, respecting social distance, and, of course, it became a source of support, help and compassion.

The fourth chapter seeks to understand what lessons people can learn from the COVID-19 pandemic and how they can be transformed for good. Cornelia C. Walther analyzes various scenarios for the further development of society, taking into account the events that have taken place, and presents the conditions under which the most positive scenario will become possible. Returning to the postulate of the interconnectedness of everything that exists on the planet, the noticeable and imperceptible influence of people on each other, we can argue that a positive scenario is possible only with cooperation, openness, compassion and understanding. As a consequence, this can lead to an improvement in the quality of life on the planet and to the transformation of relationships between people from benefit-based to mutual-help based.

The book Development and Connection in the Time of COVID-19 is interesting for its look at the events taking place in the world. Through step-by-step analysis, linking abstract concepts with practical knowledge, the author gets an integral picture of the world, in which everything is built on interaction with each other. The components that create the facets of perception, and the puzzle that supports their harmonious structure, help to understand the existing relationship and evaluate what is happening from a new point of view. All ideas are supported by specific examples, which gives the book even more weighty arguments in favor of following the proposed positive scenario for the development of events after the pandemic.

The book will be of interest to a wide range of readers, as it is written in an understandable language and in an interesting manner. It can become both the basis from which ideas for scientific research will emerge, and the support for the philosophy of people interested in this topic. The practical proposals put 
forward by the author can be adopted by both governments and supranational organizations. They will help to ensure an improvement in the quality of life of the population, strengthen the relationship between individuals in society, and will allow us to learn a lesson from the COVID-19 pandemic.

Publisher's Note Springer Nature remains neutral with regard to jurisdictional claims in published maps and institutional affiliations. 